\title{
Micro-level tests for rational expectations in South Africa
}

\author{
D.J. Marais, E. vd M. Smit* \\ Graduate School of Business, University of Stellenbosch, P.O. Box 610, Bellville, 7535 Republic of South Africa \\ W.J. Conradie \\ Department of Statistics, University of Stellenbosch, Stellenbosch, 7300 Republic of South Africa
}

Received January 1997

\begin{abstract}
The article investigates entrepreneurial expectations formation along the lines of the rational expectations hypothesis. It utilizes micro-level business survey data from the Bureau for Economic Research and distinguishes between phases of the business cycle, consumer and capital goods industries and various degrees of sectoral economic concentration. Very little evidence of weak form rationality is present in the data which concurs with similar international evaluations.
\end{abstract}

*Author to whom correspondence should be addressed.

\section{Introduction}

In the process of constructing microfoundations of macroeconomic theory it is required that entrepreneurial behaviour in a dynamic economic environment be investigated. Business survey data, such as that of the Bureau for Economic Research (BER) at Stellenbosch, offer an unique opportunity to accumulate empirical evidence on expectation formation and decision-making patterns at a micro-level. Such empirical evidence allows the verification of related micro- and macroeconomic theories in a manner distinctly different to that normally obtained from aggregated data analyses of economic behaviour.

This study investigates entrepreneurial expectations formation along the lines of the rational expectations hypothesis. The next section provides a brief overview of the hypothesis while a third section deals with measures of forecasting performance within the framework of contingency table analysis. This is followed by a fourth section which deals with the data used and method followed, while the results are presented in a fifth section, followed by a conclusion.

\section{Rational expectations hypothesis}

According to Begg (1982: xi): 'The Rational Expectations Hypothesis asserts that individuals do not make systematic mistakes in forecasting the future'. It is an economic view very similar to that of the classical economics. In essence it claims that (a) people make the best possible use of the information available to them, and that (b) prices and wages are sufficiently flexible so that the market always clears.

The rational expectations hypothesis (REH) was introduced by Muth who summarized the underlying ideas in these often quoted phrases:

'... expectations, since they are informed predictions of future events, are essentially the same as the predictions of the relevant economic theory' and

'... that expectations of firms (or, more generally, the subjective probability distribution of outcomes) tend to be distributed, for the same information set, about the prediction of the theory (or the "objective" probability distribution of outcomes)' (1961: 316).

The essentials of the REH, mentioned above, are probably stated too vaguely. Shaw draws the attention to the distinction between what is considered to be a 'stronger', and a 'weaker' level of interpretation of the theory:

'Whilst it is the strong Muthian version of the theory which has dominated academic discussion and generated the major implications and policy conclusions, other weaker statements of rational expectations formation have influenced popular debate. At one extreme, for example, the statement is taken to imply no more than that economic agents will form expectations optimally by taking all available information into consideration where availability is defined with respect to cost. Such a statement amounts to little more than the belief that agents are utility maximisers.' '... At a somewhat stronger level, ... rational expectations formation amounts to an assertion that economic agents will learn to eliminate systematic expectational error, and this version carries far greater implications for the conduct of macro-economic policy' (1984: 58).

The REH has certainly proven to be controversial. The basic assumptions of unbiased forecasts (no systematic error), and flexible prices and wages (clearing markets) have come under intense scrutiny by the Neo-Keynesian movement, and outright rejection by some Post-Keynesian fundamentalists. Some proponents recognize the limitations of the REH (see Pesaran, 1987), while others like Lucas (1980), Begg (1982) and Sargent (1983) state that even Keynes recognized the importance of uncertainty and expectations in macroeconomics but lacked the technical tools to develop his insights. A new approach is to argue for 'exploration rather than confrontation' (Wren-Lewis, 1985) to encompass the REH in a more general Keynesian framework (see Gerrard, 1994).

To test the REH a variety of properties of the theory have been transformed into testable format. It is possible to condense the variety of tests into basically four different tests. Sheffrin (1983) summarized these by stating that the theory requires tests for (i) unbiasedness, (ii) efficiency, (iii) forecast error unpredictability, and (iv) consistency.

\section{Unbiasedness}

Let the variable $V_{t-k t}$ indicate the reported expectation for variable $V_{1}$ in period $t$ made in period $(\mathrm{t}-\mathrm{k})$. 
It is common to hypothesize that an expectation of a particular variable is an unbiased predictor of the variable. A regression of form:

$$
V_{1}=a+b V_{1-k t h}+\varepsilon_{1}
$$

according to such a hypothesis, should yield the coefficient estimates $a=0, b=1$, and $E\left(\varepsilon_{1}\right)=0$.

The stochastic element, $\varepsilon_{1}$, in the equation should be uncorrelated with the expected value $V_{1-\text {-kn }}$. If that is the case, then $\varepsilon_{1}$ must be correlated with the actual realization, $V_{1}$. Hence, the variance of $V_{1}$ is larger than the variance of $V_{1-k \| l}$.

If expectations are formed rationally, it means that:

$$
\varepsilon_{1}=V_{1}-V_{1-k \text { kn }}
$$

Thus, the error term is really the difference between the eventual realization and expectation of the variable. For expectations to be rational in the Muthian sense, it is a necessary, but not sufficient condition, that the property of unbiasedness is not rejected.

\section{Efficiency}

Efficiency implies that the past history of the variable is utilized when forming the expectation, in the same way as the variable would evolve through time. In the following two regressions:

$$
\begin{aligned}
& V_{1}=a_{1} V_{1-1}+a_{2} V_{1-2}+\ldots+a_{n} V_{1-n}+\theta_{1} \\
& V_{1-1-n}=b_{1} V_{1-1}+b_{2} V_{1-2}+\ldots+b_{n} V_{1-n}+\eta_{1}
\end{aligned}
$$

the REH requires that $a_{1}=b_{i}$ for all $i$. If the REH were to be a true representation of reality, one would expect $\theta_{1}$ and $\eta_{1}$ to be identically distributed.

To eliminate the precondition that the error terms in these two equations are to be identically distributed, Mullineaux (1978) proposed that (4) be subtracted from (3) to yield:

$$
V_{t}-V_{t-1 t t}=\left(a_{1}-b_{1}\right) V_{t-1}+\left(a_{2}-b_{2}\right) V_{t-2}+\ldots+\left(a_{n}-b_{n}\right) V_{t-n}+\left(\theta_{t}-\eta_{1}\right)
$$

This relationship does not require homogeneity of variance, only independence. The one-period forecast error of a particular variable is now related to its recent history. The null hypothesis, $\mathrm{H}_{0}:\left(\mathrm{a}_{\mathrm{i}}-\mathrm{b}_{\mathrm{i}}\right)=0$ is then tested for all $i$. Note that information required in equation (5) is limited to the history of the particular variable only. Rejection of the null hypothesis does not imply that there does not exist an alternative set of information which could be used to reduce the forecast error.

The efficiency test is also referred to as the test for orthogonality. A special case of the orthogonality property of the $\mathrm{REH}$, which is related to the above Mullineaux proposal as expressed in equation (5), is that the expectation errors are serially uncorrelated with mean zero. Evans \& Gulamani (1984) proposed a test for serial correlation which is based on the regression of the forecast error $e_{t}$ (as specified in equation [2]) on its past values. This is estimated by:

$$
\varepsilon_{t+1}=\sum_{i=0}^{n} d_{i} \varepsilon_{t-i}+v_{t}
$$

for which the null hypothesis, $H_{0}: d_{i}=0$, is tested for all $i$.

\section{Forecast error unpredictability}

To earn the distinction of full rationality, the prediction error of the expectation must be uncorrelated with the entire set of information that is available to the respondent at the time the prediction is made. This will be a sufficient condition for the rationality concept. It will resemble the statistical concept of a 'sufficient estimator', which may be loosely defined as an estimator that utilizes all the available information in the sample.

This requirement implies, amongst others, that the prediction error of a variable has to be uncorrelated with historical information on prior realizations of that particular variable (as required in equation [5]). This is generally referred to as the weak version of the REH. The strong version requires that all other variables that might be known to have an effect on the predicted variable, at the time of prediction, also have to be uncorrelated with the prediction error. This is normally not determinable when testing the REH against survey data, and investigators generally revert to testing the weak version.

\section{Consistency}

When forecasts are made for a particular variable at different points in time, then the forecasts should be consistent. In the following regressions:

$V_{t-1 h}=a_{1} V_{1-1}+a_{2} V_{1-2}+\ldots+a_{n} V_{1-n}+\theta_{1}$

$V_{t-2 n}=c_{1} V_{1-21-1}+c_{2} V_{1-2}+\ldots+c_{n} V_{1-n}+\varpi_{1}$

the $\mathrm{REH}$ requires that $\mathrm{c}_{\mathrm{i}}=\mathrm{a}_{1}$ for all $i$. Assuming that this is the case, then subtracting (7) from (6) yields:

$V_{1-1 h}-V_{t-2 t}=a_{1}\left(V_{1-1}-V_{t-21-1}\right)+\left(\theta_{t}-\varpi_{1}\right)$

which is the well-known error-learning model.

These tests might appear to differ, yet they are merely alternative tests of the properties of conditional expectations. For example, if $a_{1} \neq b_{1}$, but all other coefficients in equation (5) are zero, then:

$V_{1}-V_{1 \cdot 111}=\left(a_{1}-b_{1}\right) V_{1-1}$

and according to equation (2) the difference between the expected and realized values forms the prediction error. Thus, if $a_{1} \neq b_{1}$, then the prediction error is correlated with the previous realized value of the variable, and is therefore biased. In other words, the orthogonality property of conditional expectations is violated as long as $V_{t-1}$ is contained in the information set. It can therefore be concluded that the unbiasedness and orthogonality tests are actually equivalent.

It would be desirable for expectation mechanisms to survive at least one of the above-mentioned four tests. However, conditional expectations, that is conditional on all information available at the time of the forecast, must satisfy all four properties.

\section{Measures of forecasting performance}

The four tests described ahove are appropriate when quantitative expectations data are available. However, the survey data of the BER, which will be utilized for testing the REH in expectations formation by the South African manufacturing industry, is qualitative in nature. The conventional tests for unbiasedness and orthogonality, described above, can 
therefore not be used. Instead the analytical measures developed by Kawasaki \& Zimmermann (1986) have been adopted.

Whereas nearly all empirical studies of the REH have been done with time series and regression analysis on aggregated survey data, the Kawasaki-Zimmermann approach provides a method of studying expectational phenomena at a microlevel. Frequencies of individual firms' expectations and realizations of specific variables are noted in a contingency table cross-classified by prediction and realization. The terms 'prediction' and 'forecast' will be used interchangeably with expectations. Kawasaki \& Zimmermann stressed the importance of testing expectational behaviour at the microlevel using the following simple example:

'Suppose that the whole industry consists of two homogenous groups, each of which contains the same number of producers. The first group predicts, say, $10 \%$ increases in their selling prices, while the prices decrease by $10 \%$. The second group does exactly the opposite. Therefore, the prediction is totally wrong at the micro-level. However, the prediction after aggregation turns out perfectly correct. Although this is an unlikely case, such an aggregation problem certainly persists in reality to some extent' (1986: 1336).

Kawasaki \& Zimmermann (1986) followed the Theil $(1958 ; 1966)$ proposals for a system of measures for qualitative expectations which are based upon cross-classified tables of prediction and realization data. In these tables a reported increase (prediction or realization) is indicated by a ' + ', no change in the variable by $a$ ' $=$ ' and a decrease by ' - '. The relative frequencies of prediction and realization for individual firms can be summarized as follows in the cells of the contingency table:

\begin{tabular}{|c|c|c|c|c|}
\hline & \multicolumn{3}{|c|}{ Realization } \\
\hline & & + & $=$ & - \\
\hline & + & $f(+,+)$ & $f(+,=)$ & $f(+,-)$ \\
\hline  & $=$ & $f(=,+)$ & $f(=,=)$ & $f(=,-)$ \\
\hline & 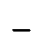 & $f(-,+)$ & $f(-,=)$ & $f(-,-)]$ \\
\hline
\end{tabular}

The sum of the relative frequencies in the diagonal from $f(+,+)$ through $f(=,=)$ to $f(-,-)$ indicates the proportion of predictions that turned out to be correct. The proportion of incorrect predictions (labelled EE) is therefore measured by:

$E E=1-[f(+,+)+f(=,=)+f(-,-)]$

Theil also proposed a measure of overestimation of level (labelled OEL) which is the proportion of predictions with levels greater than the realized levels:

OEL $=f(+,=)+f(+,-)+f(=,-)$

Similarly, a measure of underestimation of level (labelled UEL) is defined by:

$\mathrm{UEL}=\mathrm{f}(=,+)+\mathrm{f}(-,+)+\mathrm{f}(-,=)$

The bias of prediction can also be measured by considering changes as opposed to level. A measure of overestimation of change (labelled $\mathrm{OEC}$ ) indicate the proportion of predictions which are exaggerative, that is, changes were predicted but none occurred:

$\mathrm{OEC}=\mathrm{f}(+,=)+\mathrm{f}(-,=)$
The measure for underestimation of change (labelled UEC) is the sum of relative frequencies indicating conservative prediction, that is, no changes were predicted but some actually occurred:

$\mathrm{UEC}=f(=,+)+f(=,-)$

Kawasaki \& Zimmermann (1986) formulated bias indices (labelled BL and BC) for the Theil measures of level and change as follows:

$B L=\frac{(O E L-U E L)}{(O E L+U E L)}$

and

$B C=\frac{(O E C-U E C)}{(O E C+U E C)}$

Note that Kawasaki \& Zimmermann (1986) refer to these measures as B1 and B2 respectively. However, to enhance adoptability of the two measures, the references to level and change are preserved here. These parameters are reminiscent of the definition of the Goodman-Kruskal gamma coefficient for two-way contingency tables. The indices $\mathrm{BL}$ and $\mathrm{BC}$ provide simple measures of the direction of bias; they measure the degree of overestimation relative to underestimation out of the total bias. A value of ' +1 ' indicates no underestimation and only overestimation, while a value of ' 0 ' indicates balanced proportions of overestimation and underestimation, and a value of ' -1 ' indicates total domination by underestimation.

Since predictions and the associated eventual realization for individuals can vary, it is appropriate to consider statistical properties of the above measures. Assuming multinomial sampling for the trichotomous prediction and trichotomous realization, which fix the total number of observations, then the maximum likelihood estimators of the (relative) frequencies are exactly the observed sample (relative) frequencies. Since the forecasting measures are all well-conditioned functions of the relative frequencies, the calculated (sample) forecasting measures are just the maximum likelihood estimators of these measures. The estimators are therefore consistent and asymptotically normal. The asymptotic variance of a measure (M) is then determined by, either using the d-method (see Bishop et al., 1975; and Agresti, 1984) or by calculating it from:

$\operatorname{Var}(M)=\left[\frac{\partial M(f)}{\partial f}\right] \cdot \sum\left[\frac{\partial M(f)}{\partial f}\right]^{\top}$

where $f$ is the vector of relative frequencies which appear in the cross-classified table, and $\Sigma$ is the $9 \times 9$ asymptotic covariance matrix of the estimators of the relative frequencies (Kawasaki \& Zimmerman, 1986). The covariance matrix is determined by:

$$
=\left[\frac{1}{N} f_{i j}\left(\delta_{i i} \delta_{i j},-f_{i^{\prime} j^{\prime}}\right)\right]
$$

where

- the indices $i, i^{\prime}, j$, and $j^{\prime}$ can each take values 1,2 , or 3 for ' + ', '=', and '-' respectively;

- indices $i$ and $i$ ' are used for prediction, while $j$ and $j$ are used for realization in the original cross-classified table of relative frequencies; 
- indices $i$ and $j$ are also used to indicate the rows of $\sum$ while $i$ and $j$ ' indicate the columns;

- $\mathrm{N}$ is the total number of observations;

- $f_{i j}$ is a relative frequency; and

- the terms $\delta_{i j}$ take on values of 1 when $i=j$, and 0 when $\mathrm{i} \neq \mathbf{j}$.

Besides Kawasaki \& Zimmermann (1986) who used the BL and BC-measures on the German IFO survey data, it has also been applied with success by Buckle et al. (1990) and Buckle \& Meads (1991) on the New Zealand survey data, which are very similar to that of the BER.

\section{Data and method}

Since it is so difficult to determine how much additional information is needed for individual firms to be able to form their expectations rationally, only the weak form tests of unbiasedness and orthogonality on previous realized values of the particular variable are considered here. The unbiasedness test can be applied on qualitative data without further ado. The cross-classified table of prediction and realization, described earlier, already represents the structure of forecast errors. If the forecasts are unbiased, the relative frequency patterns in the off-diagonal cells in the table should not be systematically biased over time. Consistent bias would violate the unbiasedness property of the hypothesis. The BL and $\mathrm{BC}$-measures defined above can be used to measure systematic bias from the diagonal cells; the hypothesis can be rejected if either $\mathrm{BL}$ or $\mathrm{BC}$ is consistently biased over time.

Kawasaki \& Zimmermann (1986) made use of the proposals by Mullineaux (1978) to reformulate the orthogonality test (equation [5]). Mullineaux did not intend it to be used on qualitative survey data, but the reformulation provides an opportunity to apply it with a fair amount of ease. According to the orthogonality property of the hypothesis, the prediction error $\left(V t-V_{t-1 H}\right)$ is not systematically related to the past history of the variable. To test this property, it is necessary to construct a new variable referred to as a 'surprise' (denoted here by $S_{1}$ ). The above-mentioned prediction-realization table is utilized to determine the various elements of the one-period surprise, $S_{1}$. A surprise is considered positive (indicated by a ' + ' in the table) when a particular variable realizes at a higher level than has been expected. The opposite would yield a negative surprise (indicated by a '-'). Expectations which are subsequently realized are equated on the diagonal. The surprise table is then constructed (with derived changes indicated in the cells of the table) as follows:

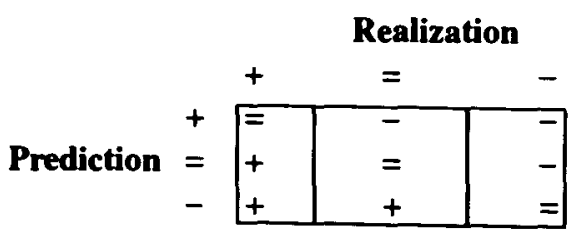

Thus, the new variable, $S_{1}$, is also trichotomous like the rest of the survey data, and it can be constructed for any variable in the BER survey data for each individual response.

Since the BL and BC-measures provide indications of systematic bias, Kawasaki \& Zimmermann (1986) suggest that it be used to test the orthogonality property as well (similar to the way it is applied for the unbiasedness test). A contingency table relating the surprise, $S_{1}$, to the one-period lagged change in the variable, $\mathrm{V}_{1-1}$, is constructed and used for estimating the $\mathrm{BL}$ and $\mathrm{BC}$-measures.

However, there is a problem with this application of the $\mathrm{BL}$ and $\mathrm{BC}$-measures. The null hypothesis for the unbiasedness test evaluates the error bias when a direct relationship between the expected value and subsequent realization of a variable is anticipated. In the Mullineaux version of the orthogonality test, the null hypothesis anticipates no correlation between the surprise and the one-period lagged change in the variable. The structure of the $\mathrm{BL}$ and $\mathrm{BC}$-measures is such that it can only be used to determine the pattern of frequencies (or predictions) of cells which do not appear on the diagonal relating the positive predictions to positive realizations, and the negative predictions to negative realizations. The null hypothesis for the orthogonality test anticipates that the majority of the observed and calculated frequencies (or probabilities) will appear in the diagonal cells. The BL and BCmeasures will therefore be of limited use in this case; it can really only be used to evaluate the error bias appearing in equation (5).

A more reliable method of testing the orthogonality property would be to estimate the Goodman-Kruskal gamma coefficient for the contingency table relating the surprise, $S_{1}$, to the one-period lagged change in the variable $V_{t-1}$. The asymptotic standard deviation of gamma can also be estimated from the information in the table, and the associated probability estimated for testing significance. A significant non-zero gamma coefficient will provide the evidence to reject the null hypothesis for the orthogonality property. This approach was proposed by Buckle et al. (1990). Despite the fact that the BL and BC-measures are not used to evaluate orthogonality (the Goodman-Kruskal gamma coefficient will fulfil that purpose), they are also estimated and reported as an indication of error bias.

Besides measuring systematic bias, the forecasting performance can also be evaluated by comparison with some naive forecasts. A simple method of generating naive predictions is to assume that the future value of a variable will be equal to the most recent realization, $\mathrm{H}_{0}: \mathrm{V}_{1}-\mathrm{V}_{1-1}=0$. This is referred to as static expectation formation, and needs to be distinguished from the REH for which the unbiasedness test null hypothesis is $\mathrm{H}_{1}: \mathrm{V}_{1}-\mathrm{V}_{\mathrm{t}-1 \mathrm{l}}=0$. The proportion of incorrect predictions (EE) of such static expectations can be calculated similarly to that of observed predictions and realizations. In this study the Static Expectations Hypothesis is included to provide a contrast background for the REH.

The data for the various BER surveys are accumulated by means of business questionnaires. The surveys are based upon the 'Konjunktur Test' approach that has been developed by the IFO Institut für Wirtschaftforschung, München, and which has been utilized to monitor the economy of the Federal Republic of Germany since November 1949. These surveys have a longitudinal character as they monitor individual responses over time and are constructed to be tendency surveys rather than opinion or markel research surveys.

The qualitative responses in the BER surveys reflect trends rather than measurable quantities. The respondents are asked to compare current business activities (including plans) with that of the corresponding period a year ago and they are 
requested to reply either 'up', 'same' or 'down'. Normally the answers to the questions are quantified by balancing the 'ups' and 'downs' and reporting the differences in a percentage format. When collated over time, the surveys form a qualitative time series with a longitudinal character and statistically analytical information.

The BER manufacturing survey data seem to be more comprehensive than most encountered in literature; it considers not only expectations and realizations of selling prices, costs of raw materials, labour costs, employment, output and stocks of finished goods, but also demand for products, stocks of raw materials, unfilled orders and hours worked. The data is collected with enough auxiliary information to enable division of the manufacturing industry into 21 main sectors. Two distinct phases in the economic cycle were identified; an expansion period from the second quarter of 1986 to the first quarter 1989 , and a recession phase from the second quarter 1989 to the fourth quarter 1991. The phases could be subdivided to examine quarterly data, to test for consistent bias. However, the number of quarterly records available is often not sufficient to conduct tests which yield significant results in the various main sectors. Therefore, the data will be grouped into four subdivisions of the manufacturing industry for investigations of the expansion and recession phases, as well as for the full cycle.

The sectorial subdivisions are as follows:

- Consumer goods;

- Capital goods;

- High economic concentration (which is associated with markets exhibiting monopolistic competition); and

- Low economic concentration (which is associated more with markets approaching perfect competition).

The CR 10 (concentration ratio for the ten largest firms) measure is utilized as an index for categorizing the threedigit industries (Du Plessis, 1978). One serious limitation in the current data set is the fact that expectations and realizations are recorded for individual establishments for one-period intervals only. If the history of parameters extending two and more periods in the past need to be examined in the orthogonality test, the number of consistent respondents diminishes markedly. Too many records are lost that way to warrant good test results from which proper conclusions can be made. The orthogonality test is therefore conducted such that the null hypothesis associated with equation (5) is reduced to $H_{1}:\left(a_{1}-b_{1}\right)=0$.

In the following sections the rationality of predictions on sales volume, production volume, orders received, unfilled orders, stocks of finished goods, general business conditions in their individual sectors, number of factory workers employed, average hours worked per factory worker, the rate of increase in average total cost and selling price per unit of production are tested for the above-mentioned sectorial subdivisions in the BER manufacturing industry survey.

\section{Results}

Total manufacturing industry

All the respondents in the BER manufacturing industry survey were pooled and analysed over the expansion phase, recession phase, and the full economic cycle. The results are presented in Tables 1, 2 and 3. In the expansion phase the estimated measures are all significant at a $10 \%$ level, that is, the null hypotheses $H_{11}: \mu=0$ ( $\mu$ representing any one of the measures reported in Table 1) are rejected at levels markedly lower than a $10 \%$ level of significance (associated probabilities $p<0.1)$. Except for six cases in the recession phase which have associated probabilities larger than $10 \%\left(\right.$ e.g. $\mathrm{H}_{1}$ : $\mathrm{BL}=0$ in the unbiasedness test for stocks of finished goods is rejected at a $50.5 \%$ level of significance $[p=0.505]$ ), the various measures are generally non-zero at a $10 \%$ level of significance. In the full economic cycle four instances of associated $p>0.1$ occur, again indicating that the null hypotheses $\mathbf{H}_{0}: \mu=0$ are generally rejected at significance levels below $10 \%$.

\section{Static expectations}

Contrary to what would be anticipated, the static expectations are (consistently) slightly more accurate than the corresponding expectations formed by the entrepreneurs (smaller prediction error). This is a surprising result and exactly the opposite to the results obtained by Kawasaki \& Zimmermann (1986). It can probably be ascribed to the political instability which plagued the South African economy right through the particular expansion and recession phases considered here. This appears to confirm the notion that a stable political and economic environment is conducive to reliable and consistent expectation formation by entrepreneurs at the micro level. The South African evidence seems to indicate that exogenous variables can have a detrimental impact on expectation formation in endogenous variables. Odd as it may seem, in times of economic instability, it is probably better to rather forecast according to the static method, which assumes that current changes are going to persist; the probability of encountering an error is lower than for the case where expectations are formed according to some complicated (rational) method.

\section{Unbiasedness test}

Considering the BL-measure for the unbiasedness test, it is concluded that entrepreneurs tend to underestimate levels of change in sales, production, orders received, unfilled orders and general business conditions during the expansion phase, and overestimate levels of change during the recession phase. The net effect over the full economic cycle indicates a significant underestimation of these endogenous variables. On the other hand, entrepreneurs seem to consistently expect factory workers to spend more hours on the job than they eventually do, although this conclusion is not so well supported in the recession phase. There also seems to be a general tendency to underestimate the rate of increase in average total cost of production, and to overestimate stock levels of finished goods, albeit not so pronounced in the recession phase.

The BC-measures for the unbiasedness test indicate a tendency to form expectations conservatively for all variables except selling price inflation rate and average hours worked. The fact that entrepreneurs rather expect variables to remain unchanged (while changes eventually occur) may also be a contributing factor to the above-mentioned surprise of static expectations being more accurate than more complicated methods. Changes in the external environment were probably so disturbing, and happened at such a rapid pace, that 
Table 1 Total industry tests: expansion phase: 2/86-1/89

\begin{tabular}{|c|c|c|c|c|c|c|c|c|c|c|}
\hline \multirow{2}{*}{\multicolumn{2}{|c|}{ Main sector }} & \multirow[b]{2}{*}{ Number } & \multirow{2}{*}{$\begin{array}{c}\text { Static } \\
\text { EE }\end{array}$} & \multicolumn{3}{|c|}{ Unbiasedness } & \multicolumn{4}{|c|}{ Orthogonality } \\
\hline & & & & EE & $\mathrm{BL}$ & BC & $\mathrm{EE}$ & GAMMA & BL & BC \\
\hline \multirow{2}{*}{ Sales } & & 6265 & 0.3657 & 0.3984 & -0.1571 & -0.2350 & 0.7464 & -0.1505 & 0.4795 & 0.5728 \\
\hline & Probability & - & 0.000 & 0.000 & 0.000 & 0.000 & 0.000 & 0.000 & 0.000 & 0.000 \\
\hline \multirow{2}{*}{ Production } & & 6160 & 0.3769 & 0.4037 & -0.1411 & -0.1964 & 0.7334 & -0.1968 & 0.4524 & 0.4988 \\
\hline & Probability & - & 0.000 & 0.000 & 0.000 & 0.000 & 0.000 & 0.000 & 0.000 & 0.000 \\
\hline \multirow[t]{2}{*}{ Orders received } & & 6061 & 0.3829 & 0.4242 & -0.1637 & -0.2256 & 0.7497 & -0.1920 & 0.4212 & 0.5256 \\
\hline & Probability & - & 0.000 & 0.000 & 0.000 & 0.000 & 0.000 & 0.000 & 0.000 & 0.000 \\
\hline \multirow[t]{2}{*}{ Unfilled orders } & & 4811 & 0.3498 & 0.3901 & -0.1486 & -0.2813 & 0.7842 & -0.1795 & 0.4365 & 0.6588 \\
\hline & Probability & - & 0.000 & 0.000 & 0.000 & 0.000 & 0.000 & 0.000 & 0.000 & 0.000 \\
\hline \multirow[t]{2}{*}{ Stocks of finished goods } & & 1183 & 0.3466 & 0.3156 & 0.1377 & -0.2281 & 0.4718 & -0.3319 & -0.1866 & 0.0927 \\
\hline & Probability & - & 0.000 & 0.000 & 0.006 & 0.000 & 0.000 & 0.000 & 0.000 & 0.059 \\
\hline \multirow{2}{*}{ General business conditions } & & 6275 & 0.4376 & 0.4696 & -0.2128 & -0.1903 & 0.7232 & -0.3038 & 0.2331 & 0.2920 \\
\hline & Probability & - & 0.000 & 0.000 & 0.000 & 0.000 & 0.000 & 0.000 & 0.000 & 0.000 \\
\hline \multirow{2}{*}{ Factory workers employed } & & 4677 & 0.3517 & 0.3761 & -0.1620 & -0.1185 & 0.5279 & -0.2900 & 0.1657 & 0.0755 \\
\hline & Probability & - & 0.000 & 0.000 & 0.000 & 0.000 & 0.000 & 0.000 & 0.000 & 0.001 \\
\hline \multirow[t]{2}{*}{ Average hours worked } & & 4707 & 0.3612 & 0.3867 & 0.0780 & 0.1114 & 0.5022 & -0.2556 & 0.2733 & -0.0742 \\
\hline & Probability & - & 0.000 & 0.000 & 0.001 & 0.000 & 0.000 & 0.000 & 0.000 & 0.002 \\
\hline \multirow{2}{*}{ Production cost inflation rate } & & 4044 & 0.2507 & 0.2713 & -0.1139 & -0.1462 & 0.8677 & -0.6161 & 0.7526 & 0.7687 \\
\hline & Probability & - & 0.000 & 0.000 & 0.000 & 0.000 & 0.000 & 0.000 & 0.000 & 0.000 \\
\hline \multirow[t]{2}{*}{ Selling price inflation rate } & & 4679 & 0.3411 & 0.3458 & -0.3115 & -0.087771 & 0.8288 & -0.6626 & 0.5395 & 0.6541 \\
\hline & Probability & - & 0.000 & 0.000 & 0.000 & 0.002 & 0.000 & 0.000 & 0.000 & 0.000 \\
\hline
\end{tabular}

entrepreneurs found it difficult to respond to the questionnaire which requires that variables be '... compared with the same quarter of a year ago .... Although convenient for the statistician, the requirement that seasonality be eliminated from the entrepreneurs' answers is conjectured to cause difficulty in generating these answers in times of political and economic instability. In an unstable economic climate, entrepreneurs would, therefore, tend to rather respond with a conservative 'no change expected', even though changes have realized in the period in which the expectations are formed.

If it can be assumed that the entrepreneurs did understand the questionnaire correctly and provided true opinions, a significant tendency to conservatively underestimate levels during the expansion phase would indicate that changes, which eventually occur, are normally upwards. Similarly, conservative overestimation of levels during the recession phase, would indicate that changes are generally downwards. Against this background, it is noteworthy that the entrepreneurs were generally optimistic about the production cost inflation rate with a consistent, conservative underestimation of levels; although the production cost inflation, compared to that of a year ago, was expected to remain unchanged, it always increased, regardless of the economic phase. This result does not appear to be consistent with the evolution of production price inflation which, according to the figures supplied by the South African Reserve Bank, showed a general downward tendency during the full economic cycle of 1986 to 1991. However, it could be argued that entrepreneurs did not really consider the change in cost inflation rate, but rather responded with their estimates of cost inflation rate levels which always tended to be lower than the levels finally experienced in the last quarter of 1991 . This argument would re- ject the assumption that they interpreted the questionnaire correctly.

\section{Orthogonality test}

The gamma coefficients, as well as the $\mathrm{BL}$ and $\mathrm{BC}$-measures, for the orthogonality tests, indicate that there were consistent biases in the relations of all the variables with their respective one-period lagged changes. From these results it can safely be concluded that surprises were systematically related to the information incorporated in the (recent) history of the respective variables. Although this conclusion is obvious from the gamma coefficients, which generally indicate a significant inverse relationship between surprise and preceding realization for each of the variables, the conclusion might not be so obvious when considering the BL-measures only. The BL-measures for the full economic cycle analysis indicate significant bias in orders received, unfilled orders, general business conditions, number of factory workers employed, and hours worked per factory worker. However, the bias appears to change direction from being all significantly positive in the expansion phase, to significantly negative in the recession phase. Note that the exact opposite is observed for stocks of finished goods. Even though the biases do not seem consistent right through the full economic cycle, it is significant in both the expansion and recession phases. Therefore, it is concluded that for these variables too, there appears to be a systematic relationship between the surprises and the information contained in the past history.

The gamma coefficients indicate that recent upward movements in the variables are predominantly associated with negative future surprises, that is, when upward movement is 
Table 2 Total industry tests: recession phase: 2/89-4/91

\begin{tabular}{|c|c|c|c|c|c|c|c|c|c|c|}
\hline \multirow[b]{2}{*}{ Main sector } & & \multirow[b]{2}{*}{ Number } & \multirow{2}{*}{$\frac{\text { Static }}{\mathrm{EE}}$} & \multicolumn{3}{|c|}{ Unbiasedness } & \multicolumn{4}{|c|}{ Orthogonality } \\
\hline & & & & $\mathrm{EE}$ & $\mathrm{BL}$ & BC & EE & GAMMA & BL & BC \\
\hline \multirow[t]{2}{*}{ Sales } & & 5167 & 0.4438 & 0.4720 & 0.0381 & -0.1186 & 0.7434 & -0.148 .3 & 0.0200 & 0.3891 \\
\hline & Probability & - & 0.000 & 0.000 & 0.059 & 0.000 & 0.000 & 0.000 & 0.214 & 0.000 \\
\hline \multirow[t]{2}{*}{ Production } & & 5108 & 0.4383 & 0.4571 & 0.0433 & -0.0921 & 0.7222 & -0.1920 & 0.0323 & 0.3391 \\
\hline & Probability & - & 0.000 & 0.000 & 0.036 & 0.000 & 0.000 & 0.000 & 0.050 & 0.000 \\
\hline \multirow[t]{2}{*}{ Orders received } & & 5027 & 0.4410 & 0.4663 & 0.0802 & -0.1187 & 0.7571 & -0.2152 & -0.0515 & 0.4161 \\
\hline & Probability & - & 0.000 & 0.000 & 0.000 & 0.000 & 0.000 & 0.000 & 0.001 & 0.000 \\
\hline \multirow[t]{2}{*}{ Unfilled orders } & & 3970 & 0.4033 & 0.4307 & 0.0573 & -0.1990 & 0.7922 & -0.2075 & -0.1320 & 0.5829 \\
\hline & Probability & - & 0.000 & 0.000 & 0.018 & 0.000 & 0.000 & 0.000 & 0.000 & 0.000 \\
\hline \multirow[t]{2}{*}{ Stocks of finished goods } & & 1124 & 0.3254 & 0.3390 & 0.0341 & -0.2000 & 0.4607 & -0.2047 & 0.0697 & 0.0289 \\
\hline & Probability & - & 0.000 & 0.000 & 0.505 & 0.000 & 0.000 & 0.000 & 0.094 & 0.573 \\
\hline \multirow[t]{2}{*}{ General business conditions } & & 5130 & 0.4158 & 0.4355 & 0.0734 & -0.0835 & 0.7409 & -0.3147 & -0.3160 & 0.3694 \\
\hline & Probability & - & 0.000 & 0.000 & 0.001 & 0.000 & 0.000 & 0.000 & 0.000 & 0.000 \\
\hline \multirow{2}{*}{ Factory workers employed } & & 5103 & 0.3296 & 0.3471 & 0.0198 & -0.0658 & 0.5414 & -0.3354 & -0.2110 & 0.1694 \\
\hline & Probability & - & 0.000 & 0.000 & 0.405 & 0.008 & 0.000 & 0.000 & 0.000 & 0.000 \\
\hline \multirow[t]{2}{*}{ Average hours worked } & & 5066 & 0.3360 & 0.3421 & 0.0179 & -0.1090 & 0.4955 & -0.3573 & -0.2032 & 0.0607 \\
\hline & Probability & - & 0.000 & 0.000 & 0.456 & 0.000 & 0.000 & 0.000 & 0.000 & 0.008 \\
\hline \multirow{2}{*}{ Production cost inflation rat } & & 5108 & 0.2678 & 0.2872 & -0.0484 & -0.0588 & 0.8375 & -0.5199 & 0.7265 & 0.7002 \\
\hline & Probability & - & 0.000 & 0.000 & 0.063 & 0.034 & 0.000 & 0.000 & 0.000 & 0.000 \\
\hline \multirow[t]{2}{*}{ Selling price inflation rate } & & 5095 & 0.3209 & 0.3386 & 0.0713 & 0.0409 & 0.7973 & -0.4072 & 0.6790 & 0.6029 \\
\hline & Probability & - & 0.000 & 0.000 & 0.003 & 0.108 & 0.000 & 0.000 & 0.000 & 0.000 \\
\hline
\end{tabular}

observed in the most recent period, the variables are generally predicted to be higher than the actual subsequent realization. The inverse is observed when the variables have adjusted downward in recent history, that is, downward movements of variables are normally associated with positive subsequent surprises.

\section{Accuracy of forecasts}

The estimated prediction errors (EE in the unbiasedness test) for cost, stocks of finished goods and price inflation are consistently smaller than that of any other variable. This phenomenon was also observed by Buckle et al. (1990) and can probably be explained by the notion that during periods of inflation (and inflation rate changes) it would be easier to predict the direction of movement in prices and costs. This view is supported by a conclusion in Nerlove \& Press (1986), as well as König et al. (1981), that French entrepreneurs tend to correctly estimate price changes, or at least have more consistency in the bias between expected and realized prices, during periods of high inflation rates. For the other variables, such as sales, production volume, and factory workers employed, there may be comparatively little change from one period (quarter) to the next, making it more difficult to predict the direction of change. This confirms the suggestion of Buckle $e t$ al. that

'... the proportion of correct expectations would be related to the distribution of reported realizations across the three categories (up, same, down)' (1990).
The relationship should be of an inverse nature, in other words, the higher the distribution, the smaller the proportion of correct expectations, or the higher the estimated error, EE.

The forecast errors estimated for the South African manufacturing industry are consistent with those found by Theil (1966), Kawasaki \& Zimmermann (1986), Stalhammar (1988), and Buckle et al. (1990). However, the New Zealand observations and results reported by Buckle et al. (1990) appear to bear the closest resemblance to that found in analysis of the BER manufacturing survey data.

\section{Price and cost expectations}

One additional interpretation of the entrepreneurial behaviour on price expectations needs to be mentioned. The EEmeasures in the unbiasedness test indicate a relatively strong association between price expectations and realizations. As pointed out by Nerlove \& Press (1986), and Buckle et al. (1990), such an association may occur either because price expectations are very good estimates (confirming the REH), or because the entrepreneurs are setting prices rather than accepting (taking) prices set by exogenous supply-demand forces. However, the consistent bias observed in the unbiasedness and orthogonality tests, indicates that the weak form REH can be rejected at the $10 \%$ level of significance. Therefore, assuming the above-mentioned impact of inflation can be ignored, it seems reasonable to assume that the manufacturing industry entrepreneurs are generally price setters, and not price takers. Whether the relatively small estimate error is a stronger function of the inflation rate, or of the characteristics of entrepreneurial behaviour, will be 
Table 3 Total industry tests: full economic cycle: 2/86-4/91

\begin{tabular}{|c|c|c|c|c|c|c|c|c|c|c|}
\hline \multirow[b]{2}{*}{ Main sector } & & \multirow[b]{2}{*}{ Number } & \multirow{2}{*}{$\begin{array}{c}\text { Static } \\
\mathrm{EE}\end{array}$} & \multicolumn{3}{|c|}{ Unbiasedness } & \multicolumn{4}{|c|}{ Orthogonality } \\
\hline & & & & EE & BL & BC & $\mathrm{EE}$ & GAMMA & BL & BC \\
\hline \multirow[t]{2}{*}{$\overline{\text { Sales }}$} & & 11432 & 0.4010 & 0.4317 & -0.0606 & -0.1785 & 0.7450 & -0.1102 & 0.2723 & $0.493 !$ \\
\hline & Probability & - & 0.000 & 0.000 & 0.000 & 0.000 & 0.000 & 0.000 & 0.000 & 0.000 \\
\hline \multirow[t]{2}{*}{ Production } & & 11268 & 0.4048 & 0.4279 & -0.0518 & -0.1466 & 0.7283 & -0.1564 & 0.2636 & 0.4294 \\
\hline & Probability & - & 0.000 & 0.000 & 0.000 & 0.000 & 0.000 & 0.000 & 0.000 & 0.000 \\
\hline \multirow[t]{2}{*}{ Orders received } & & 11088 & 0.4093 & 0.4433 & -0.0474 & -0.1755 & 0.7531 & -0.1467 & 0.2057 & 0.4774 \\
\hline & Probability & - & 0.000 & 0.000 & 0.001 & 0.000 & 0.000 & 0.000 & 0.000 & 0.000 \\
\hline \multirow[t]{2}{*}{ Unfilled orders } & & 8781 & 0.3740 & 0.4085 & -0.0505 & -0.2432 & 0.7878 & -0.1440 & 0.1781 & 0.6253 \\
\hline & Probability & - & 0.000 & 0.000 & 0.002 & 0.000 & 0.000 & 0.000 & 0.000 & 0.000 \\
\hline \multirow[t]{2}{*}{ Stocks of finished goods } & & 2344 & 0.3360 & 0.3268 & 0.0863 & -0.2142 & 0.4664 & -0.2702 & -0.0641 & 0.0619 \\
\hline & Probability & - & 0.000 & 0.000 & 0.017 & 0.000 & 0.000 & 0.000 & 0.026 & 0.081 \\
\hline \multicolumn{2}{|l|}{ General business conditions } & 11405 & 0.4278 & 0.4543 & -0.0894 & -0.1450 & 0.7312 & -0.2129 & -0.0171 & 0.3274 \\
\hline & Probability & - & 0.000 & 0.000 & 0.000 & 0.000 & 0.000 & 0.000 & 0.117 & 0.000 \\
\hline \multirow[t]{2}{*}{ Factory workers employed } & & 9780 & 0.3402 & 0.3609 & -0.0708 & -0.0919 & 0.5350 & -0.2767 & -0.0333 & 0.1252 \\
\hline & Probability & - & 0.000 & 0.000 & 0.000 & 0.000 & 0.000 & 0.000 & 0.016 & 0.000 \\
\hline \multirow[t]{2}{*}{ Average hours worked } & & 9773 & 0.3481 & 0.3636 & 0.0487 & 0.0031 & 0.4987 & -0.2993 & 0.0279 & -0.0046 \\
\hline & Probability & - & 0.000 & 0.000 & 0.004 & 0.860 & 0.000 & 0.000 & 0.051 & 0.780 \\
\hline \multicolumn{2}{|l|}{ Production cost inflation rate } & 9152 & 0.2603 & 0.2802 & -0.0764 & -0.0957 & 0.8509 & -0.5569 & 0.7383 & 0.7312 \\
\hline & Probability & - & 0.000 & 0.000 & 0.000 & 0.000 & 0.000 & 0.000 & 0.000 & 0.000 \\
\hline \multirow[t]{2}{*}{ Selling price inflation rate } & & 9774 & 0.3306 & 0.3420 & -0.1140 & -0.0173 & 0.8124 & -0.5363 & 0.6108 & 0.6278 \\
\hline & Probability & - & 0.000 & 0.000 & 0.000 & 0.357 & 0.000 & 0.000 & 0.000 & 0.000 \\
\hline
\end{tabular}

elucidated in the following discussions of the various groupings of the economic sectors in the manufacturing industry.

A similar argument can be constructed for cost expectations.

\section{Rational expectations hypothesis}

The significant biases detected for the individual variables subjected to the unbiasedness and orthogonality tests, indicate that the weak form of the REH is not supported by the BER survey data when all the respondents are pooled together in the manufacturing industry.

\section{Consumer goods industries}

The data for the expansion and recession phases, as well as for the full economic cycle were analysed in the same manner as for the total manufacturing industry. To conserve space, tables are not presented here, but are available in Marais (1995).

Very similar results are obtained (and characteristic behaviour concluded) for the consumer goods industries, although a greater number of null hypotheses were rejected at significance levels higher than $10 \%$ for the $\mathrm{BL}$ and $\mathrm{BC}$-measures in the recession and total cycle cases. It can be concluded that the weak form of the REH is not supported by the BER survey data when considering the consumer goods manufacturers.

For the consumer goods industries, the unbiasedness test estimation errors (EE) for cost and price inflation expectations are consistently smaller than those of the other variables. Whereas price inflation expectations were generally less accurate than that of stocks of finished goods for the total manufacturing industry, the opposite appears to be true for the consumer goods industry.

The conclusions derived for the total manufacturing industry, with regard to price and cost expectations, can also be derived for the consumer goods industries, that is, price expectations appear to behave more like plans than forecasts. The entrepreneurs in the consumer goods industries, therefore, seem to be price setters rather than price takers. Costs appear to have a similar plan-like character. No further light is thrown on the question (mentioned in the discussion of the total manufacturing results) about the strength of the relation between price/cost expectations and the general CPI and PPI inflation rates, on the one hand, price/cost expectations and entrepreneurial behaviour with regard to price/cost setting, on the other hand.

\section{Capital goods industries}

The results follow a similar pattern (although with a greater number of rejections of the null hypotheses at significance levels higher than $10 \%$ ) to those of the total manufacturing industry and consumer goods manufacturers.

For the capital goods manufacturers, it can also be concluded that the weak form of the REH is not supported by the BER survey data on a variety of business activities.

The above conclusions regarding cost expectations can also be derived for the capital goods industries - cost expectations appear to behave more like plans than forecasts. Although the $\mathrm{REH}$ is rejected when considering all the various measures estimated for cost inflation expectations, it is noteworthy that 
BL-measures for the unbiasedness test are consistently insignificant (no consistent bias). From a less strong rejection of the $\mathrm{REH}$, it is concluded that entrepreneurs in the capital goods industries do not seem to be such strong 'cost setters' as those in the consumer goods industries. Their forecasts of cost inflation are also consistently less accurate than that of the consumer goods industries. They seem to be more inclined to absorb cost changes, than are the consumer goods entrepreneurs.

Whereas the forecast errors in selling price inflation maintain a consistent second lowest rank, compared with the other variables in the case of the consumer goods industries, it drops to the fifth rank in the case of the capital goods industries. The magnitudes of the errors are also considerably larger than those of the consumer goods industries.

Since the REH is rejected for price expectations formation, while price forecasts are relatively inaccurate, it is concluded that entrepreneurs in the capital goods industries tend to be price takers rather than price setters. Although this conclusion is difficult to substantiate in absolute terms, it is true in this comparison of the capital goods industries' behaviour with that of the consumer goods industries. If the general assumption, that consumer goods industries are dependent upon the capital goods to produce their products, is valid, then it appears that consumer goods producers have more leverage to set their input costs (of which capital goods form a part), than capital goods producers have the power to set their prices. This conjecture obviously depends on the respondents' interpretation of the question on the rate of increase in average total cost per unit of production: does it include the cost of capital items, or not?

\section{High economic concentration group}

Once again, the data for the expansion and recession phases, as well as the full economic cycle, were analysed in the same manner as for the total manufacturing industry. The results again follow a similar pattern to those of the total manufacturing industry. In general, the conclusions derived for the total manufacturing industry analysis are therefore also valid for the high economic concentration group.

One exception, however, is the prediction error proportions for selling price inflation rate which are marginally larger for the static expectations than for the observed expectations, indicating that in the high economic concentration group entrepreneurs probably take into consideration more information than just the recent history of actual selling price inflation rates. However, the observed forecasts do not dominate the static expectations by any significant margin. Therefore, the total industry conclusions regarding the impact of political and economic instability can generally be adopted, unaltered, for the high economic concentration group.

A similar marginal superiority is noted for observed forecasts over the static expectations of general business conditions and average hours worked in the recession phase. Once again, the lack of consistency does not motivate any alterations to the adopted conclusions derived for the total industry.

From the consistent biases in the high economic concentration group results, it is generally concluded that the weak form of the REH is, again, not supported by the BER survey data on a variety of business activities.
For the same reasons as in the case of the capital goods industries (accuracy of selling price inflation dropping in rank), the high economic concentration group of industries, in comparison with the consumer goods industries, appear to be stronger price takers than price setters. Inconsistent BL-measures in the unbiasedness test also indicate that the high economic concentration group of industries seem to be more inclined to absorb costs than the consumer goods industries. It is noteworthy that three of the four sectors in the group of high economic concentration industries feature in the consumer group industries, while only one, metals, can be found among the capital goods industries. The conclusions with regard to selling prices derived for the high economic concentration industries are actually identical to that of the capital goods industries, and the opposite of the conclusions derived for the consumer goods industries. This means that the consumer goods sectors, other than tobacco, rubber products and beverages, are dominant in forming the general characteristic behaviour observed for the consumer goods industries.

The measures for expectations of stocks of finished goods are generally insignificant (except the gamma-measure in the expansion phase). There appears to be little reason to reject the weak form REH for this particular variable at the 5\% level. However, since stocks of finished goods are determined by differences in production and demand of the product(s), and expectations of these two variables do not appear to be formed rationally, the calculated insignificance of the stocks of finished goods variable is probably due to the low number of responses processed for the high economic concentration group, rather than rational expectations formation.

\section{Low economic concentration group}

The estimated measures for the low economic concentration industries show consistent biases from which it is concluded that, for the low economic concentration group, the weak form of the REH is not supported by the BER survey data.

A noteworthy phenomenon is the identical prediction error proportions in selling price inflation for the static expectations and the observed expectations. The fact that the observed errors are not significantly lower than the static errors, allows the unaltered adoption of the total manufacturing industry conclusions regarding the impact of political and economic instability. If the observed errors were significantly lower than the static errors, the conclusions would not have applied for the low economic concentration group.

A definite superiority is noted for the observed forecasts over the static expectations of stocks of finished goods in the expansion phase and full economic cycle. It does not, however, appear in the recession phase. The lack of consistency does not motivate any alterations to the adopted conclusions regarding political and economic instability.

As in the case of the capital goods and high economic concentration industries, the cost expectations appear to behave more like plans than forecasts. Again, the BL-measures for the unbiasedness test are consistently insignificant while the REH is rejected. This also leads one to conclude that entrepreneurs in the low economic concentration group are probably not such strong cost setters as those in the consumer goods industries. This is also evident from the consistently more accurate cost inflation forecasts of the consumer goods 
industries. The Food and Clothing sectors are also members of the consumer goods group while the Machinery and Metal Products sectors belong to the capital goods group of industries. The Machinery and Metal Products sectors therefore seem to dominate the behaviour with regard to cost inflation.

The ranks and magnitudes of the selling price inflation forecast errors are significantly better than that of the capital goods and high economic concentration industries. This indicates that the low economic concentration industries are relatively stronger price setters than those in the capital goods and high economic concentration groups, although not as strong as the consumer goods industries. It should again be emphasized that this conclusion would be difficult to substantiate quantitatively and that it should be viewed comparatively, and therefore more in a qualitative manner. Since two of the sectors in this group also appear in the consumer goods list of sectors, while the other two sectors are also considered capital goods industries, the characteristic behaviour of the capital and consumer goods industries with regard to selling price inflation rates seem to be balanced in the low economic concentration group. If only the ranks of the forecast errors are considered, this group would appear to bear a closer resemblance of the consumer goods than the capital goods industries.

\section{Conclusion}

The availability and qualitative nature of the BER manufacturing survey data limits the evaluation of the REH to the weak form tests of unbiasedness and orthogonality on a number of business variables. Instead of the usual regression analysis, the Theil \& Kawasaki-Zimmermann measurements have been adopted for studying the expectational phenomena at micro-level. The forecasting performance is also evaluated by comparing it with static expectations which assume that the future value of a variable will be exactly the same as the most recent realization.

In only twelve out of 150 cases analysed did the static expectations method appear to be inferior to the other methods used by entrepreneurs in forming the observed expectations. In four cases the observed and static expectations were identical. It can therefore safely be concluded that for the BER manufacturing survey of the period 1986 to 1991, entrepreneurs would generally have had better success in applying the static methods instead of forming more complicated (rational) expectations. This is probably due to a relative lack of political and economic stability in the external environment during that particular period.

This generalization about the success of static expectations needs to be qualified. From the observed twelve cases with inferior static expectations, seven are associated with stocks of finished goods in the expansion phase and the full economic cycle period. Except for the high economic concentration group, entrepreneurs generally appear to be more successful in forecasting stock levels than forming it according to the static method. In the high economic concentration industries, however, observed selling price inflation forecasts are slightly more accurate than the static expectations, while three out of the four 'identical cases' occur in selling price inflation forecasts by the low economic concentration industries. Thus, observed forecasts of price inflation and stocks of finished goods are generally more accurate than the static expectations. For all the other variables considered, the opposite is found to be true.

For the economic cycle considered, entrepreneurs appear to have been better at forecasting value-related variables, such as prices and costs, than volume related variables, such as sales, production, and demand for products (number of orders received). Forecasting the general business conditions (exogenous environment) in their respective sectors was also relatively poor. This observation would confirm the notion that entrepreneurs tend to correctly estimate price changes, or at least have more consistency in the bias between expected and realized prices, during periods of high inflation rates. For the other variables, such as sales, production volume, and factory workers employed, there may be comparatively little change from one period (quarter) to the next, making it more difficult to predict the direction of change.

The work done by Tompkinson \& Common (1983), De Leeuw \& McKelvey (1984), and Lee (1994) suggested that aggregation bias may be an important factor in the evaluation of the REH. In order to examine the acceptability of the hypothesis in certain sections of the manufacturing industry the unbiasedness and orthogonality tests were conducted on groups composed of consumer goods industries, capital goods industries, as well as high and low economic concentration industries.

From the BER survey evidence it is concluded that the REH is rejected for the total manufacturing industry as well as for the various subgroups. The concern of Lee (1994), that heterogeneity of the various sectors in the aggregated data might result in bias when considering the orthogonality tests, is not supported by the BER survey data.

Contrary to the findings of Tompkinson \& Common (1983), it cannot be concluded from the BER survey analysis that the consumer goods industries show indications of being more rational than capital goods industries in their expectation formation; the biases in both cases are consistent, although it might change direction through the full economic cycle. Furthermore, in no instance can the REH not be rejected at the $10 \%$ significance level, that is the null hypotheses $\mathrm{H}_{1}: \mu=0$ are nowhere rejected at significance levels higher than $10 \%$ in both the unbiasedness and orthogonality tests. However, the final conclusion of Tompkinson \& Common (1983) is in agreement with that derived from the BER survey results; the REH cannot be regarded as a proper explanation for expectation formation in the South African manufacturing industry.

The conclusion of De Leeuw \& McKelvey (1984) regarding large firms with 'sufficient market power' which have a strong influence on their expected (or rather planned) selling prices, cannot be confirmed with the BER survey results. The behavioural characteristics of the high economic concentration group was thought to be very similar to that of large manufacturing firms; both would either resemble monopolies (in the extreme case), or take part in monopolistic competition markets. No evidence could be found that these high economic concentration South African firms form price expectations rationally. There is also no evidence to conclude that the low economic concentration industries (as a control group) would be less rational in their price expectation formation. 
De Leeuw \& McKelvey's conjecture that large (or high economic concentration) firms, to a large extent, manage endogenous pricing changes rather than to accept price changes as dictated by exogenous market forces, can therefore not be supported. Actually the opposite may be concluded from the BER survey results: high economic concentration industries (and capital goods industries) appear to be poor price setters relative to low economic concentration industries (and consumer goods industries).

The South African evidence appears to be consistent with that found by Theil (1966) and Buckle et al. (1990), but at variance with the German experience (as noted by Kawasaki \& Zimmermann [1986]) that manufacturing firms in the IFO survey tend to be conservative in their selling price forecasts, regardless of the business cycle phase. Although the $\mathrm{BC}$ measures for selling price inflation in the BER survey analysis are generally non-zero at levels of significance higher than $10 \%$ during the recession period, they do tend to indicate a slightly exaggerative (less conservative) approach. Despite the observation that the $\mathrm{BC}$-measures are non-zero at levels of significance higher than $10 \%$ for the capital goods, high and low economic concentration industries during the expansion phase, they, nevertheless, indicate a tendency to be somewhat conservative.

The main difference between the German and South African results may be ascribed to the fact that the German firms respond to a question on expected price levels, whereas the BER questionnaire requires expectations of changes in selling price inflation levels. Although the evolution of German inflation has not been investigated, it was probably declining or stable during Kawasaki \& Zimmermann's periods of investigation. That will account for the observed tendency to overestimate (rather than underestimate) German selling price levels, regardless of the business cycle. In the South African case, the expansion and recession periods were marked by significant changes in inflation rate, as indicated by the respondents. This can probably account for the observed poor performance of South African expectations relative to the naive approach of static expectations, while in the IFO survey the observed expectations dominated the static approach by a significant margin. It is therefore conjectured that changes in the inflation rate (as an indication of economic instability), and not necessarily the current rate, may be an important factor in causing poor expectations formation, even though it is done in a complicated (rational) way.

From the BER survey results the South African manufacturing firms generally appear to be conservative in their estimates of expected changes in the various business factors analysed over the full economic cycle. In an unstable external economic climate, the risk-aversion approach seems to be dominant, and might also be indicative of entrepreneurs not having access to, or consistently utilizing all the information at their disposal when forming expectations. It might even be a case of not trusting one's own opinion of how others will form their opinions, which brings us back to Keynes' (1936) approach that all expectations should simply be viewed as exogenous and not manageable in the endogenous sense.
To summarize, the South African manufacturing business experience does not appear to provide sufficient evidence that expectations are formed rationally; not even when segments of the total industry, or a variety of business factors are examined separately. It should be emphasized that the unbiasedness and orthogonality tests conducted in this research, only provide evidence to reject the REH in its weak form, that is, although necessary evidence have been found to reject the REH in its strong form, it is not sufficient. This is in accordance with most similar evaluations of business survey data cited in literature.

\section{References}

Agresti, A. 1984. Analysis of ordinal categorical data. New York: John Wiley \& Sons.

Attfield, C.L.F., Demery, D. \& Duck, N.W. 1985. Rational expectations in macroeconomics: an introduction to theory and evidence. Oxford: Basil Blackwell.

Barro, R.J. 1976. Rational expectations and the role of monetary policy, Journal of Monetary Economics, 2: 1-32.

Begg, D.K.H. 1982. The rational expectations revolution in macroeconomics: theories and evidence. Oxford: Philip Allan Publishers Ltd.

Bishop, Y.M.M., Fienberg, S.E. \& Holland, P.W. 1975. Discrete multivariate analysis: theory an practice. Massachusetts: MIT Press.

Buckle, R.A., Assendelft, E.W. \& Jackson, L.F. 1990. Manufacturers' expectations of prices and quantities: New Zealand experience 1964-1987, Applied Economics, 22: 579-598.

Buckle, R.A. \& Meads, C.S. 1991. How do firms react to surprising changes to demand? A vector autoregressive analysis using business survey data. Paper presented to the 20th CIRET Conference. Budapest, Hungary.

De Leeuw, F.D. \& McKelvey, M.J. 1984. Price expectations of business firms: bias in the short and long run, American Economic Re view, 74(1): 99-110.

Du Plessis, P.G. 1978. Concentration of economic power in the South African manufacturing industry, South African Journal of Economics, 46(3): 257-270.

Evans, G. \& Gulamani, R. 1984. Tests for rationality of the CarlsonParkin expectations data, Oxford Bulletin of Economics and Statistics, 46:1-19.

Gerrard, W. 1994. Beyond rational expectations: a constructive interpretation of Keynes's analysis of behaviour under uncertainty, Economic Journal, 104: 327-337.

Kawasaki, S. \& Zimmermann, K.F. 1986. Testing the rationality of price expectations for manufacturing firms. Applied Economics, 18: 1335-1347.

Keynes, J.M. 1936. The general theory of employment, interest and money. London: Macmillan and $\mathrm{Co}$. Ltd.

Klamer, A. 1984. The new classical macroeconomics, conversations with the new classical economists and their opponents. Sussex: Wheatsheaf Books Ltd.

König, H., Nerlove, M. \& Oudiz, G. 1981. micro-analysis of realizations, plans, and expectations in the IFO and INSEE business texts by multivariate log-linear probability models. In Charatsis, E.G. (ed.). Proceedings of the Econometric Society European Meeting 1979: Selected Econometric Papers in Memony of Stefan Valavanis. Amsterdam: North-Holland publishing Company, pp.393420.

Lee, K.C. 1994. Formation of price and cost inflation expectations in British manufacturing industries: a multi-sectoral analysis, Economic Journal, 104: 372-385. 
Lucas, R.E. 1980. Methods and problems in business cycle theory, Journal of Money, Credit and Banking, 12: 696-715.

Marais, D.J. 1995. A study of entrepreneurial reaction patterns based on micro analyses of the Bureau for Economic Research Survey Data. Doctoral dissertation, Stellenbosch: University of Stellenbosch. (Unpublished.)

Mullineaux, D.J. 1978. On testing for rationality: another look at the Livingstone price expectations data, Journal of Political Economy, 86(2): 329-336.

Muth, J.F. 1961. Rational expectations and the theory of price movements, Econometrica, 104: 864-875.

Nerlove, M. \& Press, S.J. 1986. Multivariate log-linear probability models in econometrics. In R.S. Mariano (ed.). Advances in statistical analysis and statistical computing, 1: 117-171. JAI Press Inc.

Pesaran, M.H. 1987. The limits to rational expectations. Oxford: Basil Blackwell Ltd.

Samuelson, P.A. \& Nordhaus, W.D. 1985. Economics, 12th ed. New York: McGraw-Hill.

Sargent, T.J. 1983. An economist's foreword. In Whittle, P. (ed.).
Prediction and regulation by linear least-square methods, 2 nd ed. Minneapolis: University of Minnesota Press.

Shaw, G.K. 1984. Rational expectations: an elementary exposition. Sussex: Wheatsheaf Books Ltd.

Sheffrin, S.M. 1983. Rational expectations. Cambridge: Cambridge University Press.

Stalhammar, N. 1988. Price and demand expectations in the Swedish manufacturing industry, Scandinavian Journal of Economics, 90 : 233-243.

Theil, H. 1958. Economic forecasts and policy. Amsterdam: NorthHolland.

Theil, H. 1966. Applied economic forecasting. Amsterdam: NorthHolland.

Tompkinson, P. \& Common, M. 1983. Evidence on the rationality of expectations in the British manufacturing sector, Applied Econom. ics, 15: 425-436.

Wren-Lewis, S. 1985. Expectations in Keynesian econometric models. In Lawson, T. \& Pesaran, M.H. (eds.). Keynes' economics: methodological issues. London: Croom Helm. 